\title{
Pain characterization in Duchenne muscular dystrophy
}

\author{
Caracterização da dor na distrofia muscular de Duchenne \\ Talita Dias da Silva1, Thais Massetti1,2, Carlos Bandeira de Mello Monteiro², Isabela Lopes Trevizan², Claudia Arab, \\ Fatima Aparecida Caromano², Mariana Callil Voos², Acary Souza Bulle Oliveira3, Francis Meire Favero ${ }^{3}$
}

\begin{abstract}
Duchenne muscular dystrophy (DMD) is an X-linked recessive disorder, characterized by progressive muscle weakness. Historically, pain has not been considered to be a major symptom in DMD. Objective: To investigate the relationship between DMD and pain. Methods:We conducted a systematic review in Medline/PubMed and BVS (virtual library in health) databases. We searched for articles that showed the terms "Muscular Dystrophy, Duchenne" and "Pain" in all fields. All studies included boys diagnosed with DMD and the occurrence/amount of pain on this population. Results: Initially, there were 175 studies. 167 articles were excluded for not meeting the inclusion criteria. The remaining eight eligible studies, involving pain assessment in DMD, were analyzed. Conclusion: Pain is a frequent problem in this population and this symptom is potentially tractable. Studies conclude that pain can directly influence the quality of life of this population.
\end{abstract}

Keywords: Muscular Dystrophy, Duchenne; Pain; Neuromuscular Diseases.

\section{RESUMO}

Distrofia muscular de Duchenne (DMD) é uma doença recessiva ligada aoX, caracterizada por fraqueza muscular progressiva. Historicamente a dor não foi considerada como um dos principais sintomas em DMD. Objetivo: Investigar a relação entre DMD e dor. Métodos: Foi realizada uma revisão sistemática nas bases de dados Medline/PubMed e BVS (Biblioteca Virtual em Saúde). Foram incluídos na busca artigos que mostravam os termos "Distrofia Muscular de Duchenne" e "Dor" em todos os campos. Todos os estudos incluíram meninos diagnosticados com DMD e a ocorrência/intensidade da dor nesta população. Resultados: Inicialmente, havia 175 estudos. 167 artigos foram excluídos por não preencherem os critérios de inclusão. Então, 8 estudos elegíveis, envolvendo a avaliação da dor em DMD, foram analisados. Conclusão: A dor é um problema frequente nesta população e esse sintoma é potencialmente tratável. Estudos concluíram que a dor pode influenciar diretamente a qualidade de vida dessa população.

Palavras-chave: Distrofia Muscular de Duchenne; Dor; Doenças Neuromusculares.

Duchenne muscular dystrophy (DMD) is an X-linked recessive disorder caused by mutations in the dystrophin gene, leading to the total absence of or an abnormal, but partly functional, dystrophin protein $^{1,2}$. Duchenne muscular dystrophy is characterized by progressive muscle weakness, ambulation loss and premature death ${ }^{3}$. The lack of dystrophin results in degeneration of muscle fibers, which are replaced by fat and connective tissue $^{1}$. Boys with DMD show an initial period of gain in motor skills, followed by a plateau in acquisitions, which is then followed by a decline and ambulation loss4.

Historically, pain has not been considered to be a major part of the symptom manifestation of DMD. However, a growing number of studies indicate that chronic pain is a common symptom for people with neuromuscular diseases (NMD) ${ }^{1,5,6}$.
Chronic pain may be common, even though it is not the primary concern of patients or doctors? In some cases, pain can be the leading problem with adverse consequences on function and quality of life. Pain is described as "an unpleasant sensory and emotional experience that is associated with actual or potential tissue damage or described in such terms". Causes of pain in NMD are multifactorial, due to muscular overuse, severe contractures, vertebral fractures (caused by osteoporosis) and/or orthopedic procedures ${ }^{1,5,6}$.

Pain in NMD may be under-assessed and underestimated because of its nature and because of the context of a disorder that affects mobility. Expression of pain complaint also may be influenced by various psychological factors ${ }^{7}$. The pain perceived as related to NMD or therapeutic procedures may be

${ }^{1}$ Universidade Federal de São Paulo, Faculdade de Medicina, Departamento de Cardiologia, São Paulo SP, Brasil;

Universidade de São Paulo, Faculdade de Medicina, Programa de Pós-Graduação Ciências da Reabilitação, São Paulo SP, Brasil;

${ }^{3}$ Universidade Federal de São Paulo, Faculdade de Medicina, Departamento de Neurologia, São Paulo SP, Brasil.

Correspondence: Francis Meire Favero; Rua Botucatu, 740; 04021-001 São Paulo SP, Brasil; E-mail:ffave.nexp@latoneuro.com.br

Conflict of interest: There is no conflict of interest to declare.

Received 06 March 2016; Received in final form 20 May 2016; Accepted 01 June 2016 
denied or seen as fate by both patient and caregiver. There are also causes that are difficult to recognize and assess that represent a therapeutic problem. Such causes are a result of fears of using certain substances in patients with a potential for cardiac or respiratory risk ${ }^{7}$.

Knowledge about pain in children and adolescents with DMD is limited in terms of frequency, intensity, location, discomfort and the impact on function and quality of life. This topic is important for treatment options and understanding the impact of pain on patient compliance and the outcomes of other rehabilitation interventions ${ }^{1}$. Moreover, fatigue, pain, and affective disorders may encourage effective treatment strategy planning by health care providers ${ }^{2}$. Therefore, this study aimed to investigate the relationship between $\mathrm{DMD}$ and pain.

\section{METHODS}

This review was based on a systematic search of published articles available in June, 2015. It was conducted according to the Preferred Reporting Items for Systematic Reviews and Meta-Analyses (PRISMA) guidelines ${ }^{8,9}$.

The articles were searched for through Medline/PubMed and BVS (virtual library in health) databases, with keywords that had to be in all fields. We included articles that showed the terms: "Muscular Dystrophy, Duchenne" and "Pain".

To select the articles, we used three steps (Figure 1). The first step consisted of searching for articles in databases and reading the titles and abstracts. The second step was exclusion of studies by title, abstract, and inclusion criteria analysis. Inclusion criteria included the investigation of pain in patients with DMD as the main focus of the study and/or quantifying pain in patients with DMD. The last step was an analysis of the full text of eligible works ${ }^{10,11}$.

To increase confidence in article selection, two researchers reviewed all the potentially relevant articles independently.
After that, the researchers agreed which articles fulfilled the inclusion criteria ${ }^{10,11,12}$.

The abstracts of identified articles were screened for the following inclusion criteria (Table 1): (1) included a population with a diagnosis of DMD, and (2) pain assessment in this population. There were no restrictions about minimum sample size. Articles were excluded if they were: (1) not databased (e.g. books, theoretical papers, or secondary reviews), (2) not in English, (3) not performed with the populations identified as having DMD diagnosis, or (4) not clearly focused on pain evaluation. We planned to pool statistical data from quantitative studies within meta-analyses.

All identified studies were collected in EndNote Web (Thomson Reuters) and duplicates were removed.

\section{RESULTS}

Initially, we found 175 studies and 167 articles were excluded for not meeting the inclusion criteria (Figure 2). The data extracted from the eight selected studies are summarized in Table 2. A range of outcome measures had been used and consequently we were unable to pool data within meta-analyses.

\section{DISCUSSION}

According to the studies analyzed in this review, pain is a common and frequent problem in individuals with DMD, associated with their physical limitations and general aspects of the disease, vertebral fractures ${ }^{13}$ and scoliosis ${ }^{15}$. The youths and adults with DMD experience significant problems with pain that negatively affect their lives. Clinicians caring for these patients should investigate the nature of pain and its extent $^{6}$. Although pain is a common occurrence in boys with DMD, it may still be under-recognized ${ }^{5}$.

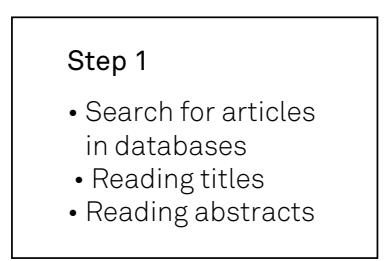

Figure 1. Steps used in studies selection.
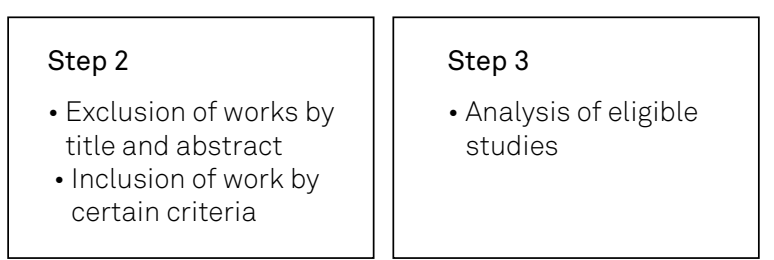

Table 1. Representation of the search strategy - PICOs criteria for the studies included.

Population: muscular dystrophy, Duchenne

Intervention: control or evaluation of pain

PICO

Comparator (control): interventions for pain control

Outcome: pain reported by patients or family members

Study design(s): clinical trials, case-control, cross-sectional, case reports and case series 


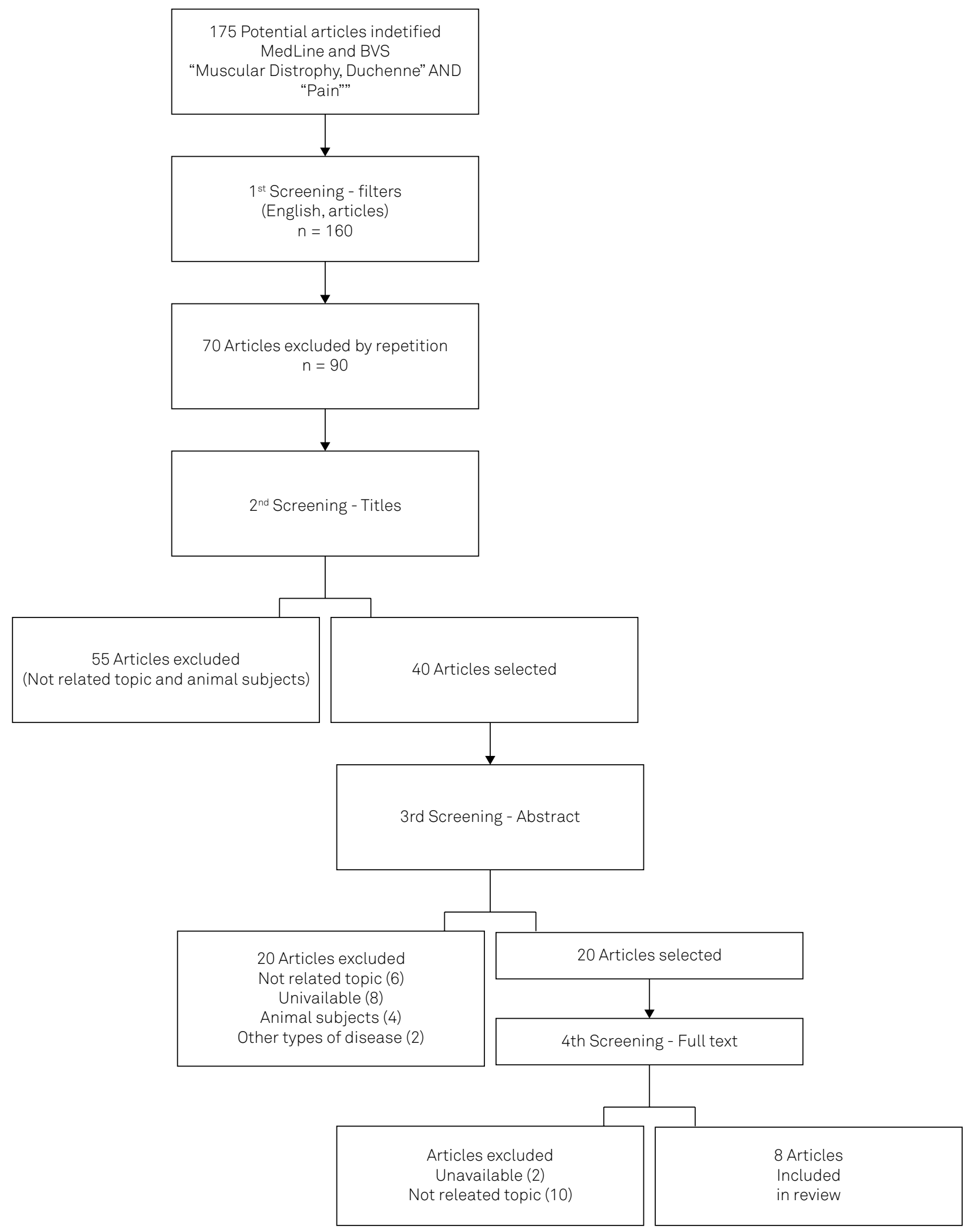

Figure 2. Literature review selection flow chart.

All eight reviewed studies contained distinct participants and sample sizes. The largest DMD population investigated was 80 patients $^{2}$. The smallest population was in the Sbrocchi et al. study of seven DMD patients ${ }^{13}$. The number of participants in studies is important to adequately portray the population. However, considering studies with disabled patients, most samples are by convenience ${ }^{11}$.

Furthermore, Lager et al. ${ }^{1}$ and Guy-Coichard et al. ${ }^{7}$ presented data from DMD and Becker muscular dystrophy patients analyzed together ( $\mathrm{n}=38$ and 128, respectively). Engel 
Table 2. Data about sample, frequency and duration of study, instruments, pain analysis and main outcomes from included studies.

\begin{tabular}{lllll}
\hline Reference & Sample & $\begin{array}{c}\text { Number of } \\
\text { assessments }\end{array}$ & Instrument & $\begin{array}{c}\text { Pain analysis / } \\
\text { Factors related }\end{array}$ \\
\hline
\end{tabular}

\begin{tabular}{|c|c|c|c|c|c|}
\hline $\begin{array}{l}\text { (Lager and } \\
\text { Kroksmark, } \\
2015)^{1}\end{array}$ & $\begin{array}{l}33 \text { adolescents with } \\
\text { DMD, } 5 \text { with Becker } \\
\text { muscular dystrophy } \\
\text { and } 17 \text { with spinal } \\
\text { muscular atrophy; Age } \\
\text { DMD group: 12-18 } \\
\text { years' old }\end{array}$ & 1 & $\begin{array}{l}\text { VAS, modified } \\
\text { version BPI and } \\
\text { questions of factors } \\
\text { exacerbating and } \\
\text { relieving pain }\end{array}$ & $\begin{array}{l}\text { Pain frequency, } \\
\text { duration, location, } \\
\text { intensity and } \\
\text { discomfort, } \\
\text { interference and } \\
\text { factors exacerbating } \\
\text { and relieving pain in } \\
\text { the last three months } \\
\end{array}$ & $\begin{array}{l}\text { Pain is a frequent problem } \\
\text { in adolescents with } \\
\text { dystrophinopathy and SMA } \\
\text { and } 69 \% \text { report pain during } \\
\text { the last three months. The } \\
\text { pain prevalence does not } \\
\text { differ significantly between } \\
\text { the diagnostic groups or } \\
\text { between ambulators and non- } \\
\text { ambulators. The mean pain } \\
\text { intensity is rated as mild and } \\
\text { the worst pain as moderate, } \\
\text { but with a wide range and some } \\
\text { adolescents rate their pain as } \\
\text { severe. The most frequently } \\
\text { reported pain sites were the } \\
\text { neck/back and legs. }\end{array}$ \\
\hline
\end{tabular}

\begin{tabular}{|c|c|c|c|c|c|}
\hline $\begin{array}{l}\text { (Pangalila et } \\
\text { al., 2015)² }\end{array}$ & $\begin{array}{l}80 \text { adults with DMD; } \\
\text { Age: } 20-44 \text { years old }\end{array}$ & 1 & $\begin{array}{l}\text { Pain was assessed } \\
\text { using the single- } \\
\text { item ratings } \\
\text { of pain of the } \\
\text { Medical Outcomes } \\
\text { Study } 36 \text {-Item } \\
\text { Short-Form Health } \\
\text { Survey }\end{array}$ & $\begin{array}{l}\text { The presence of } \\
\text { pain in the last } \\
\text { four weeks, pain } \\
\text { locations and the } \\
\text { number of locations } \\
\text { per individual, and } \\
\text { how long pain had } \\
\text { been present }\end{array}$ & $\begin{array}{l}\text { The frequent occurrence of pain, } \\
\text { very often chronic, is not reflected } \\
\text { in quality of life. The high } \\
\text { frequency of complaints in the } \\
\text { legs, arms, shoulders, and back } \\
\text { suggests musculoskeletal pain. }\end{array}$ \\
\hline
\end{tabular}

Pre and post

\begin{tabular}{|c|c|c|c|c|}
\hline $\begin{array}{l}\text { (Sbrocchi et } \\
\text { al., 2012) }{ }^{13}\end{array}$ & $\begin{array}{l}7 \text { boys with DMD; Age: } \\
8-14 \text { years old }\end{array}$ & $\begin{array}{c}2 \text { years of } \\
\text { bisphosphonate } \\
\text { therapy }\end{array}$ & $\begin{array}{l}\text { Boys report by } \\
\text { tenderness on } \\
\text { palpation over the } \\
\text { site of the observed } \\
\text { vertebral fractures }\end{array}$ & $\begin{array}{l}\text { Presence of back } \\
\text { pain due to vertebral } \\
\text { fracture }\end{array}$ \\
\hline
\end{tabular}

Intravenous bisphosphonate therapy was associated with reduction in back pain and better stabilization to improve vertebral height ratios of previously fractured vertebral bodies.

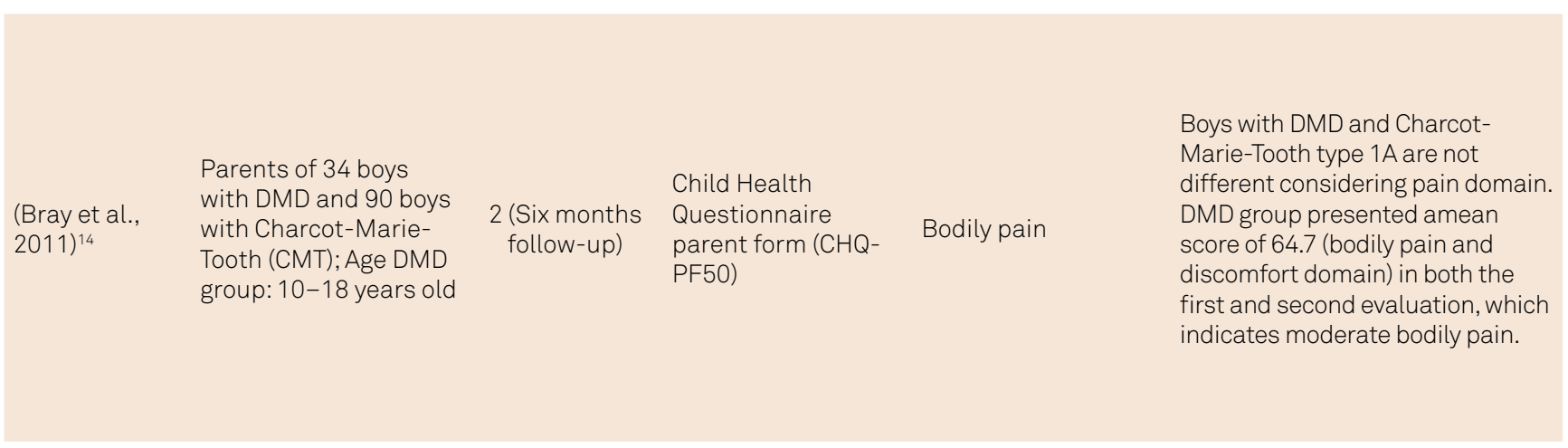

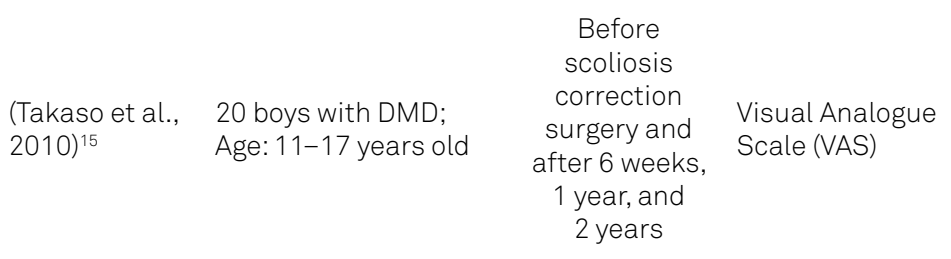

Back pain intensity
All patients had back pain before surgery. Patients reported that difficulty sitting and back pain were alleviated after surgery. The mean VAS improved from 6.2 (before surgery) to 2.5, 1.8 and 1.6 after 6 weeks, 1 year and 2 years. 
14 youths with $\mathrm{DMD}$,

6 with miotonic dystrophy, 2 with

Becker dystrophy,

2 with limb-girdle

(Engel et al., 2009) ${ }^{6}$

dystrophy, 2 with

congenital muscular

dystrophy, 1 with

facioscapulohumeral,

and 15 were classified

as "other NMD"; Age

total: 8-20 years old

Pain frequency, intensity, location,

11-point numerical rating scale and a modified Brief Pain Inventory (BPI) quality, pain interference with function and quality of life, and interventions and their effectiveness.
A total of $23(55 \%)$ of the youths reported having chronic pain. Current pain intensity was 1.3 (range $=0-6$ ), mean pain intensity over the past week was 2.4 (range $=0-7$ ), mean pain duration was 8.7 $h(S D=12.8)$. Pain in the legs was most commonly reported and $83 \%$ reported using pain medications. This study indicates that chronic pain is a significant problem in youths with DMD. These data strongly support making comprehensive pain assessment and management an integral part of the standard of care for youths with NMD.
(Zebracki and Drotar, 2008) ${ }^{5}$

43 boys with DMD and 10 with BMD; Age DMD group: 8-18 years old.
VAS, Likert scales, body outline markings, The Child Activity Limitations Interview, form indicating medical history and pain symptoms
Pain symptoms, intensity, frequency, duration, location, emotional distress due to pain, and activity limitations due to pain
Pain typically occurred at least once a week, with a mild-moderate range of intensity. Most children experienced pain for less than a few hours and little to moderate levels of emotional distress due to pain. Pain occurred most commonly in the lower back, spine, legs, and pelvic region, and was typically described as continuous pain. Children were able to manage their pain at least sometimes using techniques such as taking over-thecounter pain medications (e.g. acetaminophen, naproxen sodium), stretching, and shifting body positions. Pain typically occurred without warning at various times throughout the day, but did not disrupt sleep. Pain is a common occurrence in children with DMD or BMD, yet may be under-recognized.

\begin{tabular}{|c|c|c|c|c|c|}
\hline $\begin{array}{l}\text { (Guy-Coichard } \\
\text { et al., 2008) }\end{array}$ & $\begin{array}{l}128^{*} \text { youths with DMD } \\
\text { and BMD (total } 862 \\
\text { patients with NMD); } \\
\text { Age DMD and BMD } \\
\text { group**: Mean } 32.8 ; \\
\text { Standard Deviation } \\
12.5\end{array}$ & 1 & $\begin{array}{l}\text { Numeric scales } \\
\text { for pain intensity } \\
\text { and relief, BPI, } \\
\text { Saint Antoine Pain } \\
\text { Questionnaire, list } \\
\text { of physical factors, } \\
\text { body map }\end{array}$ & $\begin{array}{l}\text { Pain frequency, } \\
\text { characteristics, } \\
\text { topography, temporal } \\
\text { features, factors } \\
\text { influencing pain } \\
\text { intensity and impact }\end{array}$ & $\begin{array}{l}\text { Pain is frequent in hereditary } \\
\text { muscle disorders. From } 128 \\
\text { patients, } 85 \text { reported pain in the } \\
\text { last three months. The mean } \\
\text { intensity of pain was mild and } \\
\text { diffuse. Massage, physiotherapy } \\
\text { and local applications of } \\
\text { heat relieved pain. Worsening } \\
\text { factors were vertical position, } \\
\text { maintaining a fixed position and } \\
\text { changes in position and physical } \\
\text { exercise. DMD was one of the } \\
\text { diseases with greatest impact of } \\
\text { the pain on daily life. }\end{array}$ \\
\hline
\end{tabular}

DMD: Duchenne muscular dystrophy; NDM: neuromuscular disease; BMD: Becker muscular disease; SMA: spinal muscular atrophy; BPI: brief pain inventory; VAS: visual analogue scales; ${ }^{*}$ the paper had no information about each group separately; ${ }^{* \star}$ the paper had no information about minimum and maximum age. 
et al. ${ }^{6}$ analyzed patients with neuromuscular diseases in general. Bray et al.investigated pain in DMD patients according to their parents' reports 5 .

A variety of instruments was used in the reviewed studies to qualify and quantify pain. The most common instruments used in these studies were the Visual Analogue Scales (VAS) ${ }^{1,5,15}$ and the Brief Pain Inventory (BPI) $)^{1,6,7}$. Other important factors are pain frequency and duration. Some studies conducted only an assessment of pain ${ }^{1,2,5,6,7,14}$. Another three studies analyzed pain at different times: pre and post two years of bisphosphonate therapy ${ }^{13}$; before surgery and after six weeks, one year, and two years ${ }^{15}$; and in six-month follow-ups ${ }^{14}$.

As the studies mentioned above evaluated patients in different time scales, it was possible to notice pain relief after differing interventions or periods of time, but not to compare intervention protocols. Takaso et al. ${ }^{15}$ observed pain relief in DMD patients postsurgery and therapy, respectively. They showed that all patients had back pain before surgery. Their patients reported that the difficulty sitting and back pain were alleviated after surgery. The mean VAS improved from 6.2 before surgery to 2.5, 1.8 and 1.6 after six weeks, one year and two years after surgery, respectively. According to Sbrocchi et al. ${ }^{13}$, three boys reported complete back pain resolution and the remaining reported significant improvement at follow-up. Back pain improved in all patients within 30 days of bisphosphonate therapy administration, and the two boys who developed incident fractures during treatment did not report back pain ${ }^{13}$. The DMD bodily pain score remained the same after six months, in the Bray et al. ${ }^{14}$ study, with no intervention.

Studies found in this review suggested that most of the boys with DMD present with some level of pain. With interventions, such as surgery or drug administration, the boys with DMD showed some improvement on pain reports, or even complete resolution, making this a good approach to specific cases of pain. With no intervention, the pain score remained the same.

Pain assessment differed between the included studies. Sbrocchi et al..$^{13}$ and Takaso et al. ${ }^{15}$ observed back pain intensity. Pangalila et al. ${ }^{2}$ and Bray et al. ${ }^{14}$ observed bodily pain in general. Lager and Kroksmark, ${ }^{1}$ Engel et al. ${ }^{6}$, Zebracki and Drotar ${ }^{5}$ and Guy-Coichard et al. ${ }^{7}$ analyzed pain in various aspects, which included symptoms, intensity, frequency, duration, location, interference and factors exacerbating the impact of pain.

Highlighting pain frequency, duration and location, Zebracki and Drotar ${ }^{5}$ observed the occurrence of pain three or fewer times a month with a duration less than one hour. The pain was commonly in the lower back, spine, legs, and pelvic region of DMD patients, and was described as continuous. Lager and Kroksmark ${ }^{1}$ observed most of the adolescents with DMD/Becker muscular dystrophy (BMD) as having weekly pain, lasting at least three months or more and a duration from one to 12 hours.
Guy-Coichard et al. ${ }^{7}$ and Lager and Kroksmark ${ }^{1}$ showed that most patients reported the occurrence of pain in the previous three months. Lager and Kroksmark ${ }^{1}$ also showed $41 \%$ of DMD/BMD patients reporting chronic pain and, in Pangalila et al. ${ }^{2}, 65 \%$ of the subjects had had pain for longer than three months. Diffuse pain sites were found in $36 \%$ of patients in the Guy-Coichard et al. ${ }^{7}$ study. Lager's and Kroksmark's ${ }^{1}$ results are similar to those of Zebracki and $\operatorname{Drotar}^{5}$ with respect to the pain location. The most common body regions were neck/back and legs, and in three to four different locations ${ }^{1}$. Pangalila et al. ${ }^{2}$ found more than half of the DMD individuals had pain in more than one location such as legs, arms, shoulders, and back, concluding that many complaints were musculoskeletal.

The influence of pain on other factors was also explored in the reviewed studies. Zebracki and Drotar ${ }^{5}$ showed little to moderate $(47.8 \%)$ or not at all (39.1\%) emotional upset due to pain in children with DMD. Several daily activities were impacted by pain, including sitting, sleeping, and riding in a car/bus according to reports by the DMD children ${ }^{5}$. In children with DMD, the experience of pain while engaging in common behaviours may contribute to avoidance of those activities, which may lead to poor health behaviour, social withdrawal and isolation, and impaired school/work functioning ${ }^{5}$. However, the impact of pain on the daily life of DMD/BMD patients was small in the study by Guy-Coichard's et al. ${ }^{7}$. General activities and mood were the areas most affected by pain, followed by mobility and schoolwork. Sleep and relationships with others were the least affected ${ }^{7}$.

The main factors perceived by DMD and BMD adolescents to exacerbate pain were sitting, too much movement/activity and being lifted and transferred; some examples of other factors exacerbating pain were driving the power wheelchair, lying in bed, especially at night, and thinking about the pain ${ }^{1}$. The most common factors that were identified as relieving pain were resting, changing position, massage and use of painkillers. Other factors for relieving pain were doing something fun, and thinking about something else ${ }^{1}$.

Most studies show that pain affects the daily activities of boys with DMD. However, according to Pangalila et al. ${ }^{2}$, the frequent occurrence of pain symptoms, very often chronic, is not reflected in their associations with quality of life ${ }^{2}$. This is controversial and should be highlighted, considering that this is the study with the largest sample size. However, these patients were older and, possibly, daily life had already been compromised by the late stage of the disease. This may be a pitfall as it may lead to the under diagnosis of pain, with patients possibly less likely to mention it among their main complaints ${ }^{2}$.

Individual factors must be considered in these results on pain in patients with DMD. In Zebracki and Drotar's ${ }^{5}$ study, $69.8 \%$ of DMD patients received special services, $58.1 \%$ received physical therapy and $46.5 \%$ received 
occupational therapy. All participants in the study by Pangalila et al. $^{2}$ were dependent on mechanical ventilation, with $46 \%$ receiving non-invasive ventilation and $53 \%$ receiving invasive ventilation. All these participants were also wheelchair dependent, severely impaired in upper limb function and $25 \%$ used medication for pain relief. Guy-Coichard et al. ${ }^{7}$ observed that $70 \%$ of their patients were permanently wheelchair bound.

Pain reports on DMD patients by their parents showed DMD patients had a worse possible health state than the general paediatric population, including bodily pain ${ }^{14}$. Children with DMD and their parents indicated significantly more intense pain than the did physician, and children who complained of more severe pain were viewed by parents as having poorer overall emotional functioning when compared with children with low levels of pain intensity.

Youth and parent data on pain frequency, pain duration, and emotional distress due to pain were not significantly different. Parents reported significantly more limitations in activity than the children reported, and the parents reported more intense pain than the patients ${ }^{5}$.

The assessments used in the study by Lager and Kroksmark allow an understanding of the nature of pain, its scope and impact on everyday life ${ }^{1}$. They emphasize the necessity of assessing pain in a systematic manner in this population. The heterogeneity of factors perceived to exacerbate and relieve pain, as well as the consequences in everyday life, highlight the importance of an individual approach to interventions designed to reduce pain ${ }^{1}$.

Multidimensional assessments can support clinical management by improving current treatment strategies targeted toward fatigue and pain ${ }^{2}$. According to Pangalila et $\mathrm{al}^{2}$, fatigue, pain, anxiety, and depression occur frequently in adults with DMD, often concurrently, and may be underdiagnosed. Pain is more frequent in those with a poor quality of life, but still has a high prevalence in the group of adults with DMD who report good quality of life. Fatigue, pain and depression are more common in those with a poor quality of life. Effective diagnosis and subsequent treatment could alleviate the disease burden of DMD in adult men ${ }^{2}$.
Due to the progressive nature of DMD, the needs and functionality of children will change over time and should be documented in a prospective study. A longitudinal study would also help to determine causal relationships between variables ${ }^{5}$.

According Lager and Kroksmark ${ }^{1}$, further studies are required to examine the treatment efficacy of cognitive and behavioral interventions to improve the ability of adolescents to cope with, and reduce the impact of, pain. Knowledge of pain and activity limitations can be used to identify problems and barriers faced by these children and to develop interventions that target these areas ${ }^{16}$.

As Guy-Coichard et al. ${ }^{7}$ showed in their study, vertical position, maintaining a fixed position and changes in position, and physical exercise can worsen pain. This knowledge is important, as patients can use tools such as massage, physiotherapy or local heat applications to relieve pain.

Pharmacological options may be beneficial in reducing pain symptoms and, consequently, reducing activity limitations in children with DMD. In addition, cognitive-behavioral treatments designed to improve children's ability to manage and cope with pain may help to minimize the impact of pain on daily life ${ }^{5}$.

Multimodal treatment for pain in DMD patients is necessary and involves pharmaceutical, surgical, physical rehabilitation and psychosocial interventions. Future studies must analyze pain longitudinally and systematically. Longitudinal studies will help determine the causal relationships between variables. Aspects that exacerbate and relieve pain and pain consequences in daily life activities in patients with DMD must be understood in order to develop interventions to relieve pain.

\section{FINAL REMARKS}

The studies reviewed showed chronic pain as a common and frequent problem in individuals with DMD, occurring in more than one body location, usually in the lower back and legs. Pain in patients with DMD was associated to physical limitations and general aspects of the disease, vertebral fractures and scoliosis, as well as being associated with poor quality of life and emotional aspects.

\section{References}

1. Lager C, Kroksmark AK. Pain in adolescents with spinal muscular atrophy and Duchenne and Becker muscular dystrophy. Eur J Paediatr Neurol. 2015;19(5):537-46. doi:10.1016/j.ejpn.2015.04.005

2. Pangalila RF, Bos GA, Bartels B, Bergen M, Stam HJ, Roebroeck ME. Prevalence of fatigue, pain, and affective disorders in adults with Duchenne muscular dystrophy and their associations with quality of life. Arch Phys Med Rehabil. 2015;96(7):1242-7. doi:10.1016/j.apmr.2015.02.012

3. Buckner JL, Bowden SA, Mahan JD. Optimizing bone health in Duchenne muscular dystrophy. Int J Endocrinol. 2015;2015:1-9. doi: 10.1155/2015/928385

4. Glanzman AM, Flickinger JM, Dholakia KH, Bönnemann CG, Finkel RS. Serial casting for the management of ankle contracture in
Duchenne muscular dystrophy. Pediatr Phys Ther. 2011;23(3):275-9. doi:10.1097/PEP.0b013e318227c4e3

5. Zebracki K, Drotar D. Pain and activity limitations in children with Duchenne or Becker muscular dystrophy. Dev Med Child Neurol. 2008;50(7):546-52. doi:10.1111/j.1469-8749.2008.03005.x

6. Engel JM, Kartin D, Carter GT, Jensen MP, Jaffe KM. Pain in youths with neuromuscular disease. Am J Hosp Palliat Care. 2009;26(5):405-12. doi:10.1177/1049909109346165

7. Guy-Coichard C, Nguyen DT, Delorme T, Boureau F. Pain in hereditary neuromuscular disorders and myasthenia gravis: a national survey of frequency, characteristics, and impact. J Pain Symptom Manage. 2008;35(1):40-50. doi:10.1016/j.jpainsymman.2007.02.041 
8. Moher D, Liberati A, Tetzlaff J, Altman DG. Preferred reporting items for systematic reviews and meta-analyses: the PRISMA statement. Int J Surg. 2010;8(5):336-41. doi:10.1016/j.ijsu.2010.02.007

9. Hutton B, Salanti G, Caldwell DM, Chaimani A, Schmid CH, Cameron $\mathrm{C}$ et al. The PRISMA extension statement for reporting of systematic reviews incorporating network meta-analyses of health care interventions: checklist and explanations. Ann Intern Med. 2015;162(11):777-84. doi:10.7326/M14-2385

10. Massetti T, Silva TD, Ribeiro DC, Malheiros SRP, Re AHN, Favero FM et al. Motor learning through virtual reality in cerebral palsy: a literature review. MedicalExpress. 2014;1:302-6. doi:10.5935/MedicalExpress.2014.06.04

11. Menezes LC, Massetti T, Oliveira FR, Abreu LC, Herrero D, Malheiros SRP et al. Motor learning and virtual reality in down syndrome: a literature review. Int Arch Med. 2015;8:1-11. doi:10.3823/1718

12. Sampaio RF, Mancini MC. Estudos de revisão sistemática: um guia para síntese criteriosa da evidência científica. Braz J Phys Ther. 2007:11(1):83-9. doi:10.1590/S1413-35552007000100013
13. Sbrocchi AM, Rauch F, Jacob P, McCormick A, McMillan HJ,

Matzinger MA et al. The use of intravenous bisphosphonate therapy to treat vertebral fractures due to osteoporosis among boys with Duchenne muscular dystrophy. Osteoporos Int. 2012;23(11):2703-11. doi:10.1007/s00198-012-1911-3

14. Bray P, Bundy AC, Ryan MM, North KN, Burns J. Health status of boys with Duchenne muscular dystrophy: a parent's perspective.J Paediatr Child Health. 2011;47(8):557-62. doi:10.1111/j.1440-1754.2011.02022.x

15. Takaso M, Nakazawa T, Imura T, Okada T, Toyama M, Ueno M et al. Two-year results for scoliosis secondary to Duchenne muscular dystrophy fused to lumbar 5 with segmental pedicle screw instrumentation. J Orthop Sci. 2010;15(2):171-7. doi:10.1007/s00776-009-1437-5

16. Palermo TM, Witherspoon D, Valenzuela D, Drotar DD. Development and validation of the Child Activity Limitations Interview: a measure of pain-related functional impairment in school-age children and adolescents. Pain. 2004;109(3):461-70. doi:10.1016/j.pain.2004.02.023 